\title{
Tres crisis alimentarias
}

\author{
David Barkin \\ Universidad Autónoma Metropolitana y \\ Centro de Ecodesarrollo
}

\begin{abstract}
Resumen
Los cambios observados en la sociedad mexicana en los últimos decenios han provocado crisis alimentarias en el país. Este ensayo aborda esta problemática nacional que de alguna forma afecta también el desarrollo de las fronteras de México. El agro nacional se ha transformado en un emporio capitalista, perdiendo con ello su capacidad para proveer los productos básicos de consumo masivo y marginando con ellos a las mayorías campesinas. El sistema económico no ha sido capaz de ofrecer empleo o ingresos suficientes a amplios sectores de la sociedad, por lo que se ven obligados a consumir menos de lo necesario para sostener una vida sana. Incluso quienes tienen los medios están bombardeados con propaganda y limitados por los canales de distribución orillándolos a elegir productos que sistemáticamente deterioran los niveles nutricionales de su consumo diario.
\end{abstract}

Palabras clave: crisis alimentaria, agro mexicano, fronteras de México, emporio capitalista, problemática nacional.

\begin{abstract}
Changes suffered by Mexican society during the last decades have caused a crisis of food in the country. This speaks about the domestic problems that affect the development of the borders of Mexico. Domestic agriculture is becoming a capitalist emporium because it is losing its capability to provide basic goods for mass consumption; therefore this system has left unattended the majority of the people from the countryside. The economic system has not been able to offer employment or sufficient income to large groups of the society, for this reason they are forced to consume less food than they need in order to have a healthy life. Even those groups with higher income have been attacked by advertisement, but they are limited by the distributors, which force them to select products that systemically damage their daily nutrition levels.
\end{abstract}

Keywords: feeding crisis, Mexican agriculture, borders of Mexico, capitalist emporium, Mexican domestic problems. 


\title{
TRES CRISIS ALIMENTARIAS
}

\author{
David Barkin \\ Universidad Autónoma Metropolitana y Centro de Ecodesarrollo
}

México padece tres crisis alimentarias. La primera es ocasionada por su aparente impotencia de producir suficientes alimentos con destino humano para surtir la demanda existente. La segunda surge por la imposibilidad en la mayoría de los mexicanos de comprar el sustento necesario para satisfacer sus necesidades biológicas más elementales. La tercera se relaciona con el deterioro en los niveles nutricionales de los alimentos actualmente producidos en el país. Las tres están íntimamente vinculadas y surgen de un mismo proceso: el de la modernización de la economía mexicana y, por consecuencia, la extensión de las relaciones sociales del trabajo asalariado a todos los estratos de la sociedad.

Estas crisis surgen fundamentalmente por decisiones nacionales que indujeron a los capitalistas orientados al agro y a sus aliados políticos a emular el modelo norteamericano para el desarrollo del sector agrícola. Sin menospreciar la influencia del nacionalismo en el proceso, cabe destacar la importancia de ciertas tendencias globales que influyeron en los patrones de desarrollo nacional: los precios de las materias primas y bienes intermedios en los mercados internacionales determinan la conveniencia y la posibilidad de su producción local; las inversiones extranjeras cambian la canasta de productos ofrecida en los mercados nacionales; la competencia entre productores obliga a la transformación de los procesos productivos y de los mismos patrones de gasto de los consumidores.

Sólo un cambio abrupto en la posición política del sector primario de la sociedad podrá evitar que las crisis alimentarias se agudicen en el futuro. La economía política de austeridad y reactivación contempla una mayor injerencia de las señales del mercado en la asignación de recursos y un esfuerzo sistemático por restringir el poder de compra de las mayorías: las clases trabajadoras. El reordenamiento de la economía nacional reubica al país en la economía mundial: abarata la mano de obra y los recursos naturales nacionales y constituye una invitación generosa para ensanchar las inversiones extranjeras. Estos factores acelerarán aún más la extensión de las relaciones sociales de producción capitalista mediante un flujo abundante de nuevas inversiones en muchos sectores productivos y el enriquecimiento de los incentivos para canalizar los recursos nacionales a la exportación y a los mercados nacionales de consumo suntuario.

\footnotetext{
* Conferencia dictada en Ia escuela de economía de la Universidad Autónoma de Baja California Tijuana. Noviembre 14 de 1983.
} 


\section{LA CRISIS AGRICOLA}

Para entender el origen de las crisis alimentarias es preciso retomar lo que ha ocurrido durante medio siglo en la historia agro-alimentaria de México. No basta simplemente explorar la producción de alimentos, sus exportaciones e importaciones y su impacto sobre las dietas. Sin un examen riguroso de las estructuras socio-políticas que ocasionaron las transformaciones que provocaron las crisis actuales, será imposible sugerir conclusiones para modificar las tendencias actuales,

\section{El destino de los recursos agrícolas en México.}

Para sintetizar las transformaciones en el destino social y productivo de los recursos agrícolas se ha restringuido el análisis a la tierra cultivada y a los rendimientos físicos de algunos productos claves, ya que son los elementos fundamentales para comprender el comportamiento de la producción sectorial. Si bien es cierto que no son los factores que determinan la forma como se altera la asignación de recursos en el sector, sí reflejan fiel y rápidamente el impacto de las distintas medidas de política referentes a crédito, precios y subsidios de los insumos y productos que maneja el gobierno para influir en la producción. Además, el análisis del uso de la tierra agrícola simplifica la comprensión de las profundas transformaciones productivas, e integra en un solo proceso la interacción de la política y las fuerzas de la economía mundial que han resultado en la crisis que actualmente azota al país y a muchos otros en el tercer mundo.

a) El uso de la tierra. Existen dos fenómenos importantes en la evolución del uso de la tierra en México: el incremento notable en la superficie cultivada y el remarcado cambio en la distribución de los cultivos a lo largo del periodo 1940-1982. Es importante detenerse y analizar cada uno de ellos con cierto detalle.

La superficie cultivada en México se incrementó a un ritmo superior al $2.6 \%$ anual durante más de cuarenta años (véase cuadro 1). Dos factores importantes explican el crecimiento cuantitativo: la extensión del cultivo de temporal a raíz de la maduración de la reforma agraria y la disponibilidad de riego. La expansión de la superficie irrigada es resultado de una deliberada política gubernamental que se remonta a casi medio siglo. En aquella época, se empezaron a construir grandes distritos de riego en zonas antes poco susceptibles al cultivo sistemático. Desde entonces, la política se ha mantenido constante; con la creación de las primeras comisiones hidrológicas de desarrollo regional durante el régimen de Miguel Alemán, quedó asentada la primacía de este enfoque en el desarrollo agrícola para expandir la producción. Un repaso de las cuentas de la hacienda pública confirma este énfasis en la irrigación como mecanismo para fomentar el desarrollo agrícola del país: 
CUADRO 1. SUPERFICIE AGRICOLA COSECHADA 1940 - 1980

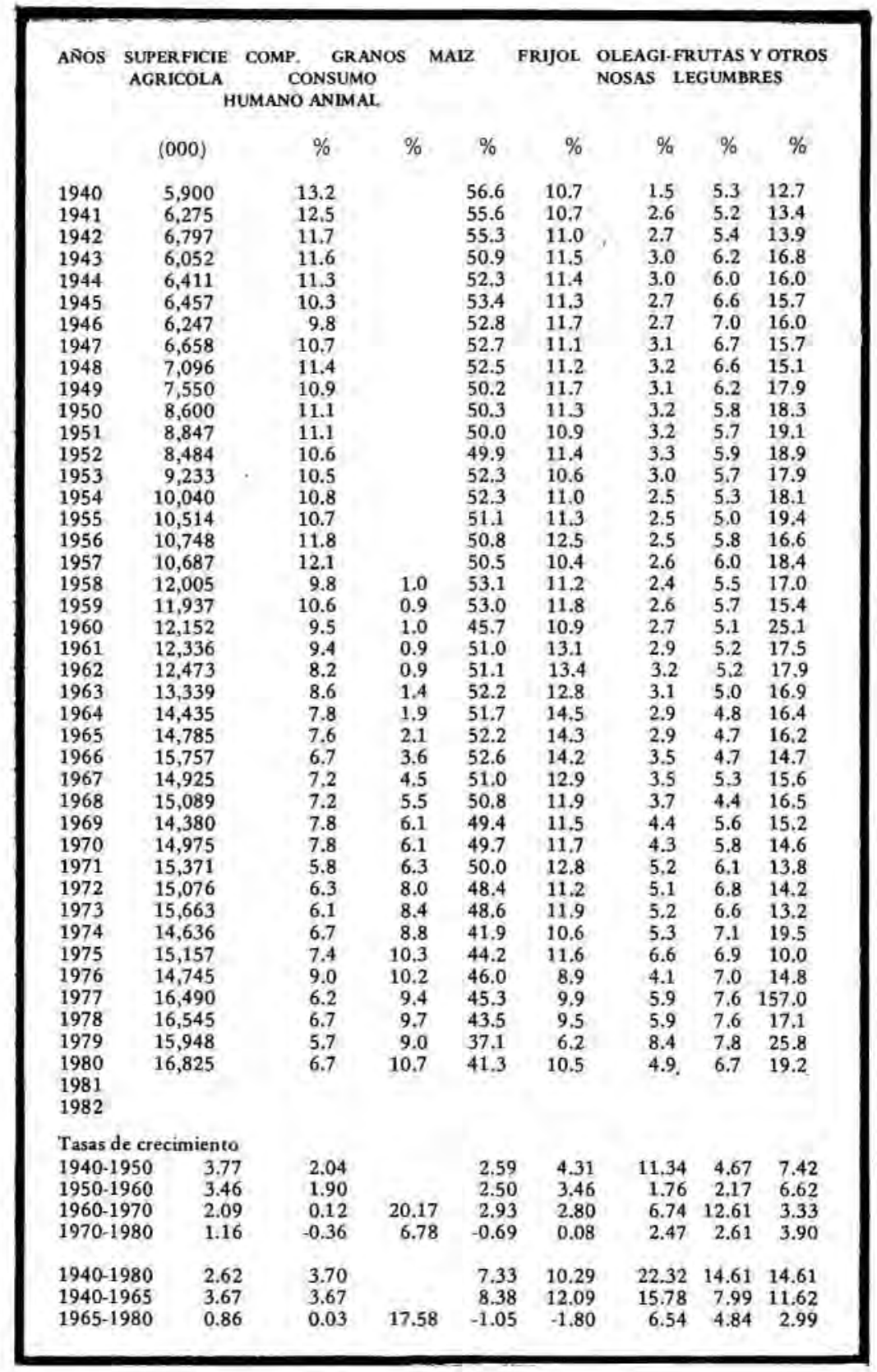


entre 1936 y 1976 casi la totalidad de la inversión pública del sector agropecuario se destinaba al riego, con una parte sustancial que llegaba a $77 \mathrm{o} / \mathrm{o}$ en 1975, y se hallaba concentrada en tres estados claves de la república: Sonora, Sinaloa y Tamaulipas. ${ }^{1}$ Los cambios observados desde 1977 obedecen a la creciente envergadura de la crisis que obligó al gobierno a elaborar nuevos programas para la revitalización de las zonas rurales.

El resultado de esta política ha sido un aumento significativo en la proporción total de la superficie nacional beneficiada con obras de riego. En 1950 csta proporción era inferior al $14 \mathrm{o} / \mathrm{o}$ mientras que un cuarto de siglo después creció a más del 22 o/o del total de la superficie cultivada. Aunque estas cifras probablemente sobreestimen la superficie realmente beneficia$\mathrm{da}$ con estas inversiones, por problemas de diversa índole es notable que hoy en día más de la quinta parte de la superficie total cultivada se encuentra dotad a con servicios de riego.

Pero el riego sólo explica una parte de la rápida expansión de la superficie cultivada en México. Su acelerada tasa de crecimiento anual debe examinarse también en el contexto del reparto agrario y de los incentivos económicos que alentaron la apertura de nuevas zonas de temporal. La distribución de nuevas áreas para la formación de ejidos claramente abrió la posibilidad de un cultivo más sistemático e intensivo de zonas anteriormente abandonadas - subutilizadas. Aún cuando es cierto que una gran parte de estas dotaciones consistieron en tierras marginales o de inferior calidad en términos de su productividad, en primera instancia el reparto mismo constituyó un incentivo al cultivo de productos básicos para el consumo familiar o local. Conjuntamente con ciertas mejorías en la calidad y la cantidad de los insumos disponibles para el cultivo de los productos básicos de consumo masivo, la mayor participación campesina en la producción, posibilitada por la reforma agraria mexicana, sin duda contribuyó a explicar el éxito del país en lograr la autosuficiencia en la producción de maíz con mayores niveles de consumo per cápita hacia finales de los años cincuentas.

En resumen, los aspectos cuantitativos del uso de la tierra agrícola en México son significativos. En cuarenta años, la superficie cultivada aumentó más de 2.5 veces, mientras que la superficie abierta al riego dio un salto de aproximadamente ocho veces. Estos datos sugieren grandes posibilidades para un incremento sustancial en la producción agrícola durante el período.

\footnotetext{
'Para análisis detallado de estos gastos véase D. Barkin y T. King, Desarrollo Económico Regional: Enfoque por cuencas hidrológicas, (México: Siglo XXI editores, 1973) D. Barkin y B. Suárez El Fin de la Autosuficien. cia Alimentaria, (México: Centro de Ecodesarrollo y Editorial Nueva Imagen, 1982) que presentan esta información en el contexto de las crisis alimentarias.
} 
b) Los rendimientos físicos. México es la cuna de la Revolución Verde. Desde principios del siglo, si no es que antes, agrónomos al servicio del Estado han experimentado con las distintas semillas disponibles, seleccionado las mejores variedades criollas o tratado de crear nuevas variedades híbridas para aumentar la productividad e identificar las plantas con mayor resistencia a las distintas plagas y a los extremos climatológicos que amenazan al agro mexicano. Las primeras experiencias en esta dirección tuvieron bastante éxito, ya que en la época cardenista el servicio de extensión agrícola reportó haber distribuido o influido en la selección de semillas que cubrieron una cuarta parte de la superficie maicera nacional, Por razones prácticas y por convicción profesional, estos profesionistas rechazaron la producción de híbridas como la mejor alternativa para incidir en la economía campesina.

Pero las grandes inversiones en tecnología asociados con la Revolución Verde no empezaron sino hasta después de la firma del convenio entre el gobierno mexicano y la Fundación Rockefeller para crear la Oficina de Estudios Especiales en 1943. Trabajando bajo la dirección de agrónomos norteamericanos, un equipo binacional logró en los siguientes lustros varias nuevas variedades de trigo que virtualmente revolucionaron su producción. Estas especies ofrecieron mayores rendimientos, mostraron una gran resistencia a diversas plagas y al problema de lodging, y una insensibilidad a lo largo del día, que las hacía adaptables a distintas latitudes desde Canadá hasta Argentina. Los rendimientos reportados aumentaron de una manera notable de 750 $\mathrm{kgs}$ por ha a principios de los años cuarentas, a casi 3.8 tons. por ha en 1980 , como se ve en la figura 1.

Los cambios en los rendimientos físicos del maíz no fueron tan espectaculares. De hecho, en el mismo lapso se elevaron solamente tres veces, de 600 a casi $1,800 \mathrm{kgs}$. por ha. Esto refleja un aumento en el uso de semillas híbridas, sobre todo en los cultivos de riego y de excelente temporal, y la disponibilidad de otros insumos como los fertilizantes, cuyo uso se ha vuelto común en el último medio siglo. La inadecuada dinámica observada en los rendimientos del maíz es producto de la poca aceptación del uso de semillas híbridas entre los productores en la mayoría de los terrenos de temporal, así como de la falta de investigaciones suficientes para la selección, el tratamiento y el uso de semillas criollas en sus comunidades.

Si bien los avances productivos del maíz fueron limitados, los cambios en rendimiento del frijol fueron aún más raquíticos. Mientras que su cultivo ha ido en constante aumento, elevándose de $700 \mathrm{mil}$ has en 1940 a casi 1,763 mil has en 1980, su productividad física promedio ha incrementado solamente de 225 a $550 \mathrm{kgs}$ por ha durante el mismo lapso. Aún más revelador del abandono tecnológico y productivo en que se encuentra este producto básico de la dieta tradicional del mexicano es el aumento significativo que se experimentó en los sesentas, cuando la superficie cultivada hab ía aumentado a casi dos millones de hectáreas, para decaer una vez más desde aquel enton- 
ces en más de $25 \%$, y reflejar la falta de rentabilidad que ofrece a los agricultores comerciales. Como consecuencia, este cultivo se ha vuelto campesino, ya que se siembra casi exclusivamente en las zonas de temporal. Una parte mínima $(13 \%)$ es producida en los distritos de riego, mientras que menos que la cuarta parte es fertilizada y la disponibilidad de semillas mejoradas es casi nula.

En contraste con los cultivos de consumo básico, la experiencia mexicana con el sorgo es inusitada en la historia agrícola a nivel mundial. En los años cincuentas su cultivo tenía tan poca importancia que no se recolectaban datos de su producción. Desde 1958 el área sembrada ha aumentado a un ritmo espectacular (véase cuadro 1), llegando a 1,750 mil has en 1982 , con aumentos en su producción superiores a $\operatorname{los} 2,750 \mathrm{o} /$. Sus rendimientos han duplicado desde 1960 (de 1,500 a más de $3,000 \mathrm{kgs}$ por ha) y han resultado en un ritmo de cambio casi tan acelerado como el del trigo. A diferencia de este último, se anticipa que su cultivo seguirá expandiéndose en los años venideros ya que los volúmenes del grano importado colocan al país como el segundo importador más importante del grano en el mundo. La explicación para este crecimiento tan acelerado se encuentra en el hecho de que este producto, que es especialmente resistente a variaciones abruptas en el régimen de lluvias y a la salinización del suelo, ha sido implantado en algunas de las zonas más productivas de México. Quizás el 40 o/o del área irrigada del país lo ha ocupado con las técnicas más modernas, ya que casi la totalidad de las semillas usadas son híbridas y más de las tres-cuartas partes de la siembra están fertilizadas. Su productividad y su potencial de mecanización lo han convertido en un favorito de los agricultores modernos, que pueden prescindir de mano de obra, lo cual facilita sus problemas de controlar el proceso de producción mientras que aseguran una buena rentabilidad. Muchos campesinos han sustituido el sorgo por el maíz, que son de la misma familia, por su mayor facilidad de cultivo, porque ofrece mejores rendimientos y menor necesidad de contratar mano de obra. Otro factor que induce a los cambios e incentiva el uso de insumos mejorados que aumentan los rendimientos, son los precios reales del grano que frecuentemente superan los precios de garantía, dada la escasez que sienten los productores de aves y puercos que lo utilizan como base para los alimentos balanceados de sus hatos.

Así, tenemos el segundo elemento que ha reestructurado al agro mexicano en el último medio siglo. Los rendimientos físicos de los cultivos básicos -los que ocupan más de los dos terceras partes de la superficie nacionalse han alterado claramente para inducir cambios importantes en la estructura de la producción. Esta revolución en la producción es evidentemente un reflejo no sólo de cambios en los conocimientos, ya que existen semillas de mayores rendimientos en maíz y frijol cuyo uso no se generaliza en México, La Revolución Verde es más un reflejo de transformaciones importantes en el modo como se toman las decisiones sobre qué, cómo y para quién producir. 
Tendremos que examinar estas determinantes para entender los cambios en la disponibilidad de alimentos en México.

c) El uso de la tierra. La recomposición de los cultivos sembrados también contribuyó a transformar profundamete al agro mexicano. Se ve claramente el desplazamiento de los cultivos básicos por algunos íntimamente relacionados con la modernización capitalista en la agricultura y la expansión consecuente del complejo ganadero. Muy concretamente, se puede detectar un marcado crecimiento de productos forrajeros a partir de 1965 , y la misma tendencia con respecto a las oleaginosas unos años más tarde.

Pero la reestructuración de la producción agrícola en el país es más compleja que una simple expansión hacia los productos ganaderos. Se notó un aumento importante en la superficie cultivada con frutas y legumbres, estimulado ciertamente por las nuevas inversiones agroindustriales en las cuales participaron activamente capitales nacionales y extranjeros. Asimismo, se puede observar una mayor preocupación en distintas partes de la administración pública para el cultivo rentable de mayores volúmenes de productos comerciales y sobre todo exportables, como el café y el tabaco. Otros productos fueron estimulados casi exclusivamente por la iniciativa privada, que respondieron a los incentivos del mercado; tal es el caso de la expansión del garbanzo como producto de exportación y alimento porcino, y de la vid como insumo para la producción agroindustrial nacional.

La contraparte de esta diversificación fue, inevitablemente, la disminución relativa de la importancia de los granos básicos en la producción nacional. De ocupar más de tres cuartas partes de la superficie total a principios de los años cuarentas, los cuatro cultivos básicos (arroz, frijol, maíz y trigo) disminuyeron de un modo tajante su participación a menos de la mitad en 1979 , tendencia que se contrarrestó por lo menos brevemente con las acciones que regían el programa del Sistema Alimentario Mexicano (SAM). Sin embargo, aun esta pequeña alteración en las tendencias históricas no duró mucho y el nuevo gobierno ratificó claramente su compromiso para promover la sustiución de los granos básicos por cultivos más rentables. Las ventajas comparativas que fueron canonizadas como doctrinas para asignar recursos nacionales y estructurar al comercio exterior en sexenios pasados han sido resucitadas al tal grado que el actual Secretario de Agricultura fue motivado a reafirmar su convicción de que "quizá le convenga más al país producir sólo 70 u 80 por ciento del maíz y 90 o del frijol que se requieren e importar la diferencia, a cambio de exportar otros productos agrícolas más remunerativos (...) Si le damos demasiada importancia (al cultivo del maíz), no podríamos diversificar nuestra agricultura y la economía." (Excelsior, 22 de abril de 1983, p, 10-A).

En resumen, el panorama global del uso de la superficie agrícola en México muestra un gran dinamismo. Tanto en el plano cuantitativo como en el 
cualitativo se evidencia un ritmo acelerado de transformación que algunos catalogan como modernización. Este dinamismo refleja en buena medida el éxito de las políticas gubernamentales al promover el desarrollo agropecuario a cualquier precio. En los últimos decenios, el aumento sustancial en la superficie cultivada ha facilitado la aplicación de los conocimientos básicos disponibles para forjar una nueva estructura productiva, una estructura que inexorablemente está profundizando las crisis a que se hace mención al principio de este artículo.

La ganaderización del agru mexicano.

La reorganización del agro es particularmente notable a partir de 1965. Varios factores se conjugaban para impulsar el resurgimiento de los productos orientados a la ganadería mayor y menor. En nuestra hipótesis sostenemos que la ganaderización es parte integral del proceso de internacionalización del capital, es decir, del proceso de modernización que ha transformado gran parte de la producción primaria en capitalista y ha sujetado a los demás productores a las reglas del mercado capitalista que se ha implantado en México. En este apartado se examinan los mecanismos que operan para que se siga transformando la estructura productiva del sector primario en los años venideros.

La intensificación de la producción ganadera va acompañada de profundas alteraciones en los métodos de trabajo en todos sus aspectos. Estos cambios generalmente son imitativos de procesos que ya han sido implementados en otros lugares, particularmente en los Estados Unidos de América. El traslado de estos procesos a México responde a una necesidad del capitalista de mantenerse competitivo con otros productores, que adaptan sus patrones de producción para tratar de aumentar la rentabilidad de sus inversiones. En cuanto a la ganadería mayor, se ven las adaptaciones en la implantación de técnicas de estabulación permanente para cuencas lecheras y para la producción de becerros de engorda. Aunque todavía no se observan semejantes procesos en la producción de carne para el mercado nacional, el gobierno mismo trata de combatir la resistencia de los productores, ofreciendo la alternativa de la siembra de pastos y el mejoramiento genético como parte de sus programas de modernización ganadera. Quizá más impactante aún podrían ser sus esfuerzos por reorganizar los mercados nacionales de carne, y por tratar de crear nuevos organismos que competirían con los monopolistas tradicionales y reducirían los costos de comercialización. En un pequeño segmento muy especial del mercado, el de cortes finos, la intensificación de la producción está muy avanzada como parte del proceso de racionalización.

En otro orden, la implantación de granjas para la cría intensiva de pollos y su posterior procesamiento en línea, ha resultado en la producción industrial de la carne de pollo, de una manera semejante a las fábricas norteamericanas o europeas. Solamente su susceptibilidad a problemas fitosanitarios y la 
incompleta capacidad de controlar los factores ambientales limitan la posibilidad de realmente sustraer esta actividad del sector primario. Más recientemente, el mismo enfoque utilizado en la producción avícola se ha aplicado a la porcicultura con resultados semejantes.

Tanto en la ganadería mayor como en la menor, entonces, se ha visto un proceso dinámico de intensificación de la producción con cambios bruscos en la tecnología y los insumos requeridos. Para la agricultura, esto ha implicado demandas insatisfechas para el sorgo y las pastas oleaginosas, principales ingredientes en los alimentos balanceados preparados para aquella actividad. A la vez, se ha visto un reacomodo de la superficie productiva, que ha reducido la necesidad del pastoreo extensivo en algunas partes del Norte, a la vez que se ha expandido en el trópico húmedo, donde se puede mantener un número mucho mayor de cabezas por hectáreas que en las zonas áridas. Como se señaló en el apartado anterior, el reacomodo no sólo se refiere al pastoreo, sino a la composición de la producción agrícola que demuestra el dinamismo de los productos forrajeros a expensas de los cultivos básicos de consumo humano.

El reordenamiento de la producción agrícola y ganadera parece ser resultado de una estrategia "internacional" - una estrategia fomentada tanto por las autoridades nacionales como por intereses capitalistas internacionalesmediante la cual preparar al país para ejercer un mayor papel en el abastecimiento de ganado y carne al mercado norteamericano. Dicha estrategia también incluye la tecnificación de la producción para el mercado nacional, generaliza sistemas modernos de trabajo que surten productos a un reducido estrato de la población nacional, y así también erosiona la base productiva de sustento de los campesinos, quienes no constituyen un grupo fácilmente manejable por el capital. Aunque la estrategia misma no se encuentra explícitamente delineada, es consistente con los objetivos y las necesidades del proceso de expansión internacional del capital, que son los siguientes: 1) reorganizar la producción para incorporar al reino de producción capitalista productos históricamente controlados por grupos de productores no-capitalistas o de la familia para facilitar el control del trabajo por el capital y de tal modo expandir las bases de generación de ganancia; y 2) reorganizar y agrandar los mercados para mercancías que emanan de la producción capitalista, mediante la reducción de la capacidad social y nacional de ser autosuficientes y la creación de demandas para nuevos productos o para la transformación de materias primas en productos terminados.

La diversificación de la agricultura.

Con la ganaderización, también se dio una diversificación del producto agrícola en otras direcciones. Es decir, una parte decreciente de la superficie total y de los recursos disponibles para apoyar a la agricultura está dedicada directamente a la producción de cultivos básicos de consumo masivo. 
Ahora está destinada directamente a los productos pecuarios y a otros productos con destino industrial o extranjero. Los datos originales sobre el uso de la superficie cultivada (cuadro 1) claramente muestran esta tendencia negativa en la participación de los cultivos básicos en la producción agrícola.

Parte del mismo fenómeno es la paulatina pero omnipresente presión de las principales frutas y legumbres (salvo el frijol que está incluido como producto básico) de aumentar su participación en el uso de la superficie nacional. En esta categoría se mezclan varios elementos que deben destacarse, a saber: 1) la importancia de productos de exportación como fresas, pepino y tomate para la generación de divisas y empleo pero que estén sujetos a las altibajas de los mercados externos de destino; 2) la limitada capacidad de compra de los consumidores nacionales para muchos de estos productos; 3) la ausencia de un proceso de control de calidad de los productos y los procesos de producción que exponen a los trabajadores y a los consumidores a peligros por el uso de plaguicidas; y 4) los problemas epidemiológicos que resultan de la falta de un tratamiento adecuado de las aguas negras usadas para regar en ciertas partes del país y del manejo de los productos entre su cosecha y su consumo.

El caso del algodón ilustra todavía otro fenómeno característico de la agricultura en México, que ahora se generaliza. Aquí se ve claramente un ciclo completo de auge y retracción de un producto que es eminentemente de exportación. Su auge ocurrió en un periodo de fuerte demanda ocasionada por eventos bélicos y por otros factores en los mercados mundiales. La respuesta mexicana fue de expandir la superficie cultivada para aprovechar las oportunidades económicas que se ofrecieron. Pero el auge duró pocos años, y sólo permitió a unos cuantos enriquecerse desmesuradamente, mientras que el aumento en costos ocasionados por plagas y otros factores restringieron las ganancias de los que llegaron después y motivaron una rápida contracción de los sembradios en los años setentas. El historial del algodón, como el del café que le sigue en el tiempo, es típico de la nueva posición de la agricultura comercial en México: su suerte ahora está íntimamente ligada a los cambios en los precios de unos cuantos productos en los mercados internacionales, precios controlados en muchos casos por algunas de las empresas transnacionales más grandes del mundo. Las dislocaciones sociales y económicas a nivel regional provocadas por el auge y la caída del cultivo del algodón o del café son enormes y la imposibilidad de implementar un programa de planificación a más largo plazo resulta muy costosa. La respuesta anárquica a las altibajas en los precios ocasiona fuertes alteraciones en los planes de producción de un año al otro; asimismo aumenta la dependencia del país en el exterior a la vez que le resta posibilidades de enfrentar y solucionar sus propias necesidades más apremiantes.

Esta diversificación no podía estar acompañada de un mecanismo de planificación del sector agropecuario. Como consecuencia, la diversificación, 
lejos de representar una plena ganancia para el país en términos de una mejor dieta o una menor exposición a los peligros de una exportación poco diversificada, ha ocasionado una mayor dependencia con el exterior. Desde 1965, las importaciones de productos básicos necesarios para mantener el desafortunado estado nutricional de la población han crecido al grado de que convirtieron el superávit en el comercio exterior de productos agropecuarios en déficit durante varios años. La crisis que se hizo aparente en 1980 motivó al Estado a reasignar recursos a los productos básicos de consumo humano durante un breve periodo, pero la doctrina de las ventajas comparativas se fortaleció más que nunca con la respuesta a la crisis global del sistema. El gobierno parece estar determinado a eliminar el criterio de autoabastecimiento como guía de la planeación agrícola con la consecuente marginación progresiva de la mayor parte de los productores y sus terrenos.

\section{LA CRISIS DE ALIMENTACION}

Los cambios en la estructura productiva del agro han ido acompañados de modificaciones semejantes en los demás sectores de la economía. La industrialización del país ha generado un portentoso aparato productivo que ha proporcionado muchos de los artefactos de una sociedad moderna, sin contribuir a solucionar los problemas fundamentales de cualquier sociedad: ofrecer un empleo digno y productivo a todos sus miembros y asegurar un abasto mínimo de los bienes y servicios necesarios para la convivencia social.

La explicación para esta problemática descansa en el modelo de industrialización y en los mecanismos adoptados por el gobierno mexicano para impulsarla. No hace falta repasar una larga literatura sobre el tema, basta apuntar algunos de los elementos más destacados del proceso. El primero es la decisión de hacer descansar la industrialización en los patrones de consumo heredados de los países industrializados y en la distribución del ingreso extremadamente concentrada. Los planes desarrollistas comenzaron por dar impulso a la fabricación de productos de consumo final, con programas para un aumento progresivo en el grado de integración nacional. Como en tantos otros ejemplos latinoamericanos, se eligió a la industria automotriz como el eje de este esfuerzo, con el argumento de que estimularía la creación de industrias de autopartes, insumos básicos como vidrio, acero y hules, y profesiones derivadas como la mecánica, la metalmecánica, etc. Con la ventaja del análisis de la experiencia histórica es bastante fácil identificar las fallas de este enfoque: las industrias implantadas no pretendieron satisfacer las necesidades de servicios o mercancías de la mayoría de la población, mientras que la elección de industrias y tecnologías no generó los empleos requeridos para ocupar a los nuevos aspirantes a la fuerza de trabajo, y mucho menos para absorber los millones que fueron desplazados del agro a raíz de su modernización. También se descubrió que la nueva estructura industrial creó una dependencia económica con el exterior todavía más aguda por la necesidad de importar insumos para sostener el funcionamiento del nuevo aparato productivo y de los bienes de capital para su mantenimiento y renovación. 
Un segundo elemento del desarrollo mexicano descansó en la promoción de un programa de maquiladora que aprovecharía la cercanía de los EUA y la abundante mano de obra disponible a bajos costos. Se erigió una estructura legal y una infraestructura física para alentar la implantación de empresas que ensamblaran las distintas partes electrónicas o vestuarias que podrían exportarse sin ocasionar fuertes gravámenes impositivos. Las inversiones del gobierno mexicano resultaron enormes y después de casi veinte años de vida el programa ha generado aproximadamente 130,000 empleos, menos del $1 \mathrm{o} / \mathrm{o}$ de la población económicamente activa, y grandes problemas sociales.

Sin entrar en otros detalles del proceso de desarrollo mexicano, como la política monetaria y cambiaria que sistemáticamente favorecieron a ciertos grupos minoritarios de la población, promovieron una desnacionalización del aparato productivo e incentivaron la fuga de capitales, se puede sintetizar su impacto sobre la alimentación. El desarrollo del agro libró a una gran cantidad de personas que se desplazaron a las ciudades para ofrecer su fuerza de trabajo, lo cual deprimió los salarios industriales. A la vez, la modernización del agro primero ofreció una creciente oferta de alimentos baratos para sostener a la población urbana y después por su propio éxito no pudo continuar. $\mathrm{La}$ industrialización inicialmente también creó grandes oportunidades, mediante la expansión de las clases medias y la respuesta a sus crecientes demandas con mercancías de fabricación nacional. La fuerza de trabajo creció y se hablaba de un "milagro mexicano" precursor de una nueva etapa histórica de los países que llegarían a desarrollarse en el molde capitalista. Las celebraciones nunca obligaron a un examen cuidadoso de las contradicciones ocasionadas por la desigualdad inherente en el proceso que con el tiempo explotarían en cargas financieras insostenibles e imposiciones internacionales de gran envergadura. ${ }^{2}$ Lo que es más, se aseguró que el petróleo ofrecería los recursos necesarios para corregir las desigualdades heredadas, pero aún durante su auge nunca se ofrecieron planes que atacaran a fondo los orígenes estructurales y productivos de los problemas.

El resultado de esta historia es la polarización de la sociedad mexicana en todas sus dimensiones. En materia alimentaria los efectos son dramáticos. Las encuestas realizadas en los ochentas revelaron que más de 25 millones de mexicanos (de un total de 75 millones) nunca consumen carne, que menos de 30 millones tienen acceso regular a la leche y que 19 millones tienen un consumo calórico y proteínico diario inferior a los mínimos necesarios. (Michael Redclift, "El estado frente al campo", Nexos No. 47., noviembre de 1981, pp. 11-16).

\footnotetext{
2 Muchos analistas académicos sí insistieron en los peligros del modelo vigente, previendo inclusive los extremos de la situación actual, pero tuvieron poca injerencia en las decisiones políticas a pesar de su fácil acceso a la prensa nacional y la opinión pública, Véanse, por ejemplo, David Barkin y Gustavo Esteva: Inflación y Democracia. México: Siglo XXI editores, 1982.
} 
El fenómeno de la malnutrición no es nuevo. Ya se había hecho notar durante decenios por el mismo Instituto Nacional de la Nutrición, entre otros. Durante muchos años los niveles nutricionales de la gran mayoría de la población, incluyendo los campesinos, se habían mejorado a raíz de los incrementos en la productividad y la producción. Con los cambios estructurales en la producción agrícola, el creciente desempleo y los problemas de abastecimiento interno ocasionados por la disminución de la producción básica, el problema de la escasez de alimentos se volvió crisis a finales de los setentas. Las voluminosas importaciones de granos básicos hicieron disparar los precios en los mercados no controlados, es decir, en las zonas rurales donde la mayor parte de los productores son deficitarios en estos productos y en los barrios más pobres de las áreas urbanas. Lo que sí es novedad es una oferta inadecuada de alimentos básicos para abastecer la demanda existente, una demanda que sostenía los magros niveles nutricionales predominantes, Con el aumento en los precios rurales y el creciente desempleo resultante de la crisis, quizá será mas fácil llegar a la autosuficiencia nacional, ya que la demanda está reduciéndose notablemente, pero ¿̨a qué costo?

\section{LA CRISIS NUTRICIONAL}

Finalmente cabe hacer notar un impacto importante de las transformaciones productivas sobre el estado nutricional de la población. Se ha vuelto un lugar común lamentar el efecto de los cambios en la dieta sobre los niveles nutricionales de la población en México; es tema de denuncia, de exhortación y de resignación. Los economistas lo caracterizan como resultado del ejercicio de la voluntad individual en el mercado.

Sin comentar en detalle los estudios al respecto, valga la pena reiterar algunos de sus hallazgos principales. El procesamiento industrial ha provocado un encarecimiento de la dieta de la población y un deterioro en su calidad. El Instituto de Nutrición aparentemente no se cansa de advertir el alto consumo per cápita de azúcar, sobre todo en los refrescos embotellados, mientras que el Instituto Nacional del Consumidor le hace eco, insistiendo en la irracionalidad de la mayoría de los productos que sustituyen a las preparaciones alimentarias caseras. Eligen como blanco especialmente los alimentos y la propaganda orientados a los niños y el alto costo que representan las distintas presentaciones ofrecidas en el mercado. El resultado de los cambios en los patrones de consumo de la población ha sido, según se afirma, una merma sensible en la calidad de la dieta y una reducción en el consumo de los satisfactores necesarios para mantener el bienestar físico entre aquellos grupos de la población que sí tienen los medios económicos suficientes para garantizar un consumo mínimo adecuado. Entre los grupos más pobres, los efectos de la difusión de las llamadas "comidas chatarra" han sido mucho más desvastadores, ya que actualmente estos grupos gastan un mayor porcentaje de sus ingresos de esta manera. Muchos notan la enorme influencia de las empresas transnacionales en estas transformaciones, pero cabe señalar que las empresas 
nacionales también adoptan las mismas pautas en el diseño de su producción y sus estrategias de penetración en el mercado.

\section{EN CONCLUSION}

Los cambios observados en la sociedad mexicana en los últimos decenios han provocado las crisis alimentarias a que se hizo referencia. El agro ya no es capaz de surtir los productos básicos de consumo masivo, por haberse transformado en un emporio capitalista y marginado a las mayorías campesinas. La economía no es capaz de ofrecer empleo o ingresos a vastos segmentos de la sociedad, y como consecuencia se ven obligados a consumir menos de lo necesario para sostener una vida sana. finalmente, hasta los que tienen los medios están bombardeados con propaganda y limitados por los canales de distribución a eligir productos que sistemáticamente deterioran los niveles nutricionales de su consumo diario.

Estas crisis son producto de una profunda transformación de la sociedad mexicana. Se emprende la producción para la ganancia, y la competencia entre productores les hace adoptar sistemas de trabajo y fabricar productos que les son redituables. Muy a menudo, existen conflictos entre las exigencias de las decisiones que toman para asegurar sus ganancias y los intereses de los consumidores. Como consecuencia, los conflictos más importantes se agudizan entre la necesidad que tiene la sociedad de asegurar una oferta adecuada de alimentos y la dinámica del mercado que la empuja en otras direcciones;entre el imperativo de crear empleos productivos y las elecciones de industrias y tecnologías que los destruyen; y entre la urgencia de mejorar los niveles nutricionales y las dificultades de aunar calidad y ganancias.

\section{BIBLIOGRAFIA}

BARKIN D. y B. Suárez. El fin del Principio: La semilla y la seguridad alimenticia México: Centro de Ecodesarrollo y Editorial Océano 1983.

ROZO C. y D. Barkin. Los alimentos y la Internacionalización del Capital en: El Trimestre Económico, No. 199, septiembre de 1983, pp, 1603-1626. 